\title{
TRANSFORMING COMPETITIVENESS BY INTRODUCING DIGITAL PLATFORMS
}

\author{
a. NOSOVA, Olga* \\ b. LYPOV, Volodymyr.
}

a. V.N. Karazin Kharkiv National University, Ukraine. *Corresponding author(olgano59@gmail.com)

b. Department of Economic Theory, Institute for Economics and Forecasting NAS of Ukraine, Ukraine.

\section{COPYRIGHT NOTICE:} the Creative Commons Attribution (CC BY) license (https://creativecommons.org/licenses/by/4.0/ ).

\section{CITE THIS PAPER:}

Nosova, Olga; Lypov, Volodymyr (2021). "Transforming Competitiveness by Introducing Digital Platforms" Journal of World Economy: Transformations \& Transitions (JOWETT) 1(03):11. DOI: https://doi.org/10.52459/jowett13111221

\begin{abstract}
The purpose of the proposed paper is to study the specific factors shaping the benefits of information platforms as an innovative institutional form and model of doing business. Active dissemination of the business model of online platforms radically transforms the competitive landscape of the market environment. The task of determining the sources and mechanisms for studying the changes that are taking place is being updated. New areas of competition include competition between hierarchical and network structures, between global «structuring» platforms, competition in dominant platform ecosystems, the interaction between platforms operating in competitive markets, competition between organizers and users, and between platform users. The impact of platforming on crossindustry, regional and international competition is determined. The sources of competitive advantages of platforms are investigated. These include reliance on data as the main factor of production, changing the cost structure of entering the market; the possibility of building largescale networks, niche specialization, combining the effects of increasing the scale of production and demand, multihoming, multi productivity, network effects.
\end{abstract}

\section{KEYWORDS}

Competition, Competition Policy, Digital Economy, Market Power of Platforms, Online Platforms Effects, Transforming Competitiveness. 


\section{INTRODUCTION}

Significant reduction of market entry costs and the possibility of rapid scaling up lead to the restructuring of markets for goods and services under the influence of digitalization. There is a rapid change in priority business models. The digital platforms spread causes not just the emergence of new forms and methods of competition, but systemic change. The scale and geographical coverage of markets are growing. There are opportunities to deepen differentiation, create new ones.

Among the ten most successful corporations in the market growth of the second decade of the 2000s, six are leaders in the platform business. They operate in the areas of software, IT equipment, trade, financial intermediation. In turn, there are successes and significant economic profits of the corporations United Health Group (health), Costco Wholesale (a network of self-service warehouses club type), Lvmh Moet Henne (manufacturer of luxury items under the brands Christian Dior, Louis Vuitton, Givenchy, Guerlain, Moët \& Chandon, Hennessy, Chaumet, etc.), TSMC (development and production of semiconductor products). They come from using a platform business model in the process of organizing production and promoting its products to consumers. It is also worth noting the undisputed leadership of the campaigns representing the United States. At the same time, only one corporation from the EU and Southeast Asia was represented in the group of leaders. In a situation where the emphasis on the use of digital technologies, reliance on individual entrepreneurs, opens the door to world markets, the volume of the domestic market is no longer a decisive factor in achieving competitive advantage.

\section{REVIEW OF THE LITERATURE}

The importance of research into new sources of success in competition, formed as a result of the digitalization of the economy, is growing. A comparison of the concepts of «digitization» and «digital economy» shows that digitization is the basis of the digital economy, which determines the direction of the world development of the economy and society. It defines the main modern trend in the economy and society, based on the transition to a digital format presenting information, thus stimulating the availability and reliability of storage and transmission of big data (Nosova \& Pavlov, 2021, p. 36). At the beginning of the new millennium, researchers J. Laffont and J. Tirole (2001) justified the need to review the competition policy of a state in the context of the spread of network business models. Then Rochet and Tirole (2003) proposed a theoretical model of competition for individual entrepreneurs with bilateral markets. D. Evans (2003; 2007) traces how the peculiarities of competition in the markets of individual entrepreneurs affect the changes in regulatory policy associated with the spread of multilateral markets. B. Caillaud and B. Jullien (2003) go far beyond the announcement in the title of the work the "chicken and egg problem", which faces the organizers of the new digital platforms. The focus is on studying their potential in the formation of imperfect price competition. Their factors include the presence of indirect external effects of the network, the possibility of using non-exclusive services of several intermediaries, price discrimination based on tracking data about users and their behavior. At the same time, the openness of individual markets, according to the authors, mitigates price competition. 
Emphasis is placed on the strategy of "divide and rule" when one side of the market is subsidized and the profit is obtained from the other. Researchers argue that the introduction of transaction fees is a key tool in pricing and business strategies, and the concentration of market power entrepreneurs does not necessarily lead to market inefficiencies.

On the contrary, the authors of the study «Like It or Not? The Impact of Online Platforms on the Productivity of Incumbent Service Providers» (OECD, 2019) note the negative impact of the monopolization of individual markets on productivity growth. In turn T. Doganoglu, and Wright (2010) consider the policy of "divide and rule" as a means of preventing competitors from achieving a network effect in the relevant market. The authors recognize the practice of using the restriction of the buyer's rights to products purchased by individual entrepreneurs as an additional tool to improve competitive positions in the market.

The understanding of the peculiarities of competitive markets formed in certain areas of digital platforms activity is deepening. J. Haucap and U. Heimeshoff (2013) in the spotlight markets for search engines, trading platforms, and social networks address the problem of defining the controversial role of the Internet as a factor in monopolizing markets or intensifying competition and its implications for competition policy. Further, N. Duch-Brown (2017) studies the factors that determine the characteristics of the competitive environment of digital platforms, which operate in the areas of e-commerce, distribution of digital applications, advertising, and social media. A similar study of the specifics of competition in the emerging markets of search engines, rental housing, music applications, and price comparison in the field of car insurance, social networks was conducted by the Ministry of Enterprise, Innovation, and Crafts of the United Kingdom by A. Lilico and M. Sinclair (2017).

S. Hyrynsalmi, A. Suominen, and M. Mantymaki investigate the impact of multihoming on the peculiarities of competition in emerging digital platforms markets (2016). Instead, M. Armstrong focuses on studying the impact of restrictions on multihoming, as a tool of competition policy of individual entrepreneurs, on the behavior of potential sellers and buyers (2006).

The impact of the specifics of competitive relations in digital platform markets on the social efficiency of the economy is in the spotlight of the research by R. Casadesus-Masanell, F. Ruiz-Aliseda (2009). Recognition of the role and importance of the platform business model has been reflected in the emergence of research focused on the experience and identification of features and principles of competition policy at both national and international levels.

To these issues are devoted in the works of N. van Gorp, O. Batura (2015), and M. Schallbruch, H. Schweitzer, A. Wambacha (2019). C. Nochebuena and B. Juárez prepared a report on the Asia Pacific Economic Cooperation (APEC) seminar on competition policy about the regulation of Internet Platforms in the AsiaPacific region (2019). Researchers investigate a wide range of aspects of the transformation of competitive relations related to the introduction of Information and Communications Technology (ICT) and the spread of a 
platform business model. However, the sources of determining the success of the digital platforms are considered only in passing, as a prerequisite for further analysis. Only some components of ensuring the competitive success of the platform model are considered.

This paper tries to provide a comprehensive study of specific factors shaping the benefits of information platforms as an innovative institutional form and model of doing business and includes qualitative, structural, dialectical, historical, comparative, and genetic analysis. In the process of working on the topic, logicalhistorical and systemic research methods have been used.

\section{DIGITAL PLATFORMS IN THE COMPETITIVE MARKETS}

The introduction of digital platforms as an innovative model of international business leads to the restructuring of the entire structure of competitive relations in the global economy. Giant multinational corporations, which dominated international business in the last third of the twentieth century, are giving way to highly mobile entrepreneurs. Behind the change in the names of corporations - global leaders in the transition from the dominance of the hierarchical business structure described by R. Coase (1937) to horizontal network structures (Hrytsenko, 2013). Transnational Corporations (TNCs) themselves started this process. The abandonment of own production assets, the involvement of independent producers in the creation of the final product, the formation of global value chains (GVC) laid the foundation for an alternative institutional model.

At the same time, competition between digital platforms and traditional hierarchical structures complements by several other areas of competition. A fundamentally new direction of competition arises due to the formation of global platforms - system integrators. They provide software, information base, the virtual space for interaction of other digital platforms. Among them, we can highlight such as Microsoft, Google, and Facebook.

Reliance on virtual data as the main factor in the production activities of digital platforms opens new opportunities for international, interregional, cross-sectoral competition. The transition from the conveyor, chain model of the production process to network, active development, and dissemination of 3D printing create opportunities for duplication of individual components of value creation, their prompt correction in response to changes in consumer behavior, technological, resource capabilities. Competitive advantages of the global nature of the organization of production activities are supported by the advantages of regionalization of international trade. The use of digital platforms opens up opportunities for both the creation of new and combination, replacement in one product, a single technology of several products of different sectors of the economy. This creates the basis for the development of intersectoral competition. Suffice it to cite examples of competition between traditional (television, printed books, newspapers, magazines) and electronic media. In turn, smartphone manufacturers have demonstrated unconditional competitive advantages over manufacturers in several industries. Manufacturers of electric cars on autopilot have competed with manufacturers of cars with internal combustion engines. 
Competition is unfolding between digital platforms focused on providing the same services. The story of how Chinese Didi Chuxing prevented Uber from entering the Chinese trucking market quickly fades into history. Today, dozens of similar digital platforms in Ukraine compete with each other for potential customers.

The interest of digital platforms organizers in expanding the range of participants in its ecosystem, relying in this process on the satisfaction of their interests, has its downside in redistribution in favor of the value-added created by cooperation. This level of competition - the competition between the core digital platforms and the participants of its ecosystem concretized, in cases where the core of the platform in parallel with some of the participants offers the same products. Corporations Microsoft, Amazon can serve as the most illustrative examples.

An important component of ensuring the successful competitive position of digital platforms itself is the ability, due to the network nature of the ecosystem, to maintain competitive relations between individual participants in the ecosystem. Of course, each of these levels of competition has its characteristics, but, at the same time, the general factors of ensuring the benefits of a platform institutional form and business model remain.

\section{COMPETITION BETWEEN TRADITIONAL HIERARCHICAL STRUCTURES AND DIGITAL PLATFORMS}

The most obvious results of competition between traditional hierarchical and network organizations, the organizational core of which consists of digital platforms, manifest in the changing structure of world economic leaders. Traditional, built on a hierarchical basis, TNCs, representing the automotive, electronics, and retail industries gave way to digital platforms. The data presented in Table 2 are indicative. According to the results of 2020, none of the traditional TNCs was included in the list of the ten largest corporations in the world by market capitalization. The difference in the economic potential of alternative business models is illustrated by the following example. In 1990, three of Detroit's leading automotive corporations received nominal revenues of $\$ 250$ billion, with a market capitalization of \$ 36 billion, and attracting 1.200 .000 employees. In 2014 , the three largest corporations in Silicon Valley with a comparable nominal income ( $\$ 247$ billion) had a market capitalization above one trillion dollars. At the same time, the number of employees was only 137 thousand people (Chui \& Manyika, 2015).

It should be noted that the formation of information platforms was a continuation and development of the logic of TNCs in global markets. The latter in the '80s of the twentieth century launched the process of dumping fixed assets and the transition to contractual relations with independent suppliers of individual components of products. However, there are significant differences between TNCs and information platforms that operate globally, such as Google or Facebook. 
TNCs, discarding peripheral, low-profit, labor-intensive elements of the production process, retained control over the activities of contract manufacturers. The tools of such control were technological, financial dependence, the dependence of participants in the GVC on the terms of sales of their product. As a result, the formally horizontal system of relations acquired a hierarchical feature.

In turn, the horizontal nature of relations within the digital platforms' ecosystem combined with the maintenance of constant monitoring of the internal state and external environment, strong feedback from customers, the possibility of duplication, variation, rapid changes in individual components of the production process. Table 1 shows the scope of activity of the largest companies by market capitalization and depicts the leading positions of the TNCs in the IT sphere, oil, and natural gas production, electric vehicles (MarketCap, $\underline{2021)}$.

Table 1: Scope of activity of the largest companies by market capitalization (January 2021).

\begin{tabular}{|c|c|c|c|c|c|c|}
\hline Rating & Company & $\begin{array}{l}\text { Market } \\
\text { capitalizati } \\
\text { on USD } \\
\text { billion }\end{array}$ & $\begin{array}{l}\text { Annual } \\
\text { change } \%\end{array}$ & $\begin{array}{l}\text { Number of } \\
\text { employees } \\
\text { (Rating by this } \\
\text { indicator) }\end{array}$ & Field of activity & Country \\
\hline 1 & Apple & 2.340 & 61,52 & $147.000(134)$ & $\begin{array}{l}\text { Developer of IT equipment and software, online portals } \\
\text { for music, movies, and software }\end{array}$ & USA \\
\hline 2 & $\begin{array}{l}\text { Saudi } \\
\text { Aramco }\end{array}$ & 2.040 & 1,02 & $79,000(301)$ & $\begin{array}{l}\text { Oil and natural gas production. The largest oil } \\
\text { company, the second-largest explored crude oil reserves }\end{array}$ & Saudi Arabia \\
\hline 3 & Microsoft & 1.708 & 29,99 & $163,000(119)$ & $\begin{array}{l}\text { Bing search engine software and services, cloud } \\
\text { solutions. Windows computer operating system }\end{array}$ & USA \\
\hline 4 & Amazon & 1.652 & 64,95 & $1,125,300(2)$ & $\begin{array}{l}\text { Online store offering a wide range of goods. The } \\
\text { world's largest assortment of books, CDs, and videos. } \\
\text { Marketplace, Amazon Kindle, Amazon Fire HD, Fire } \\
\text { TV, HDMI stick Fire TV Stick, and Echo speech } \\
\text { recognition system. }\end{array}$ & USA \\
\hline 5 & $\begin{array}{l}\text { Alphabet } \\
\text { (Google) }\end{array}$ & 1.283 & 20.65 & $132.121(158)$ & $\begin{array}{l}\text { Holding company, Google LLC continues to exist as a } \\
\text { subsidiary. }\end{array}$ & USA \\
\hline 6 & Tencent & 862 & 74.56 & $62885(256)$ & $\begin{array}{l}\text { The technology company provides messaging services, } \\
\text { support for social networks, Internet media, Internet } \\
\text { services, multiplayer online games (MMO, MMORPG), } \\
\text { e-commerce, and online advertising. }\end{array}$ & China \\
\hline 7 & Tesla & 802 & 671,7 & $48,016(472)$ & $\begin{array}{l}\text { Production and sale of electric vehicles, energy storage } \\
\text { devices, and photovoltaic systems. }\end{array}$ & USA \\
\hline 8 & Facebook & 781 & 17,91 & $56,653(415)$ & $\begin{array}{l}\text { Social network Facebook, Instagram video and photo- } \\
\text { sharing app, WhatsApp and Oculus VR messenger, } \\
\text { virtual reality equipment maker }\end{array}$ & USA \\
\hline 9 & Alibaba & 718 & 17,22 & $120535(178)$ & Retail platform & China \\
\hline 10 & TSMC & 601 & 125,45 & $48,752(473)$ & Semiconductor manufacturer & Taiwan \\
\hline
\end{tabular}


The types of corporate cultures characteristic of traditional TNCs and digital platforms (DP) differ significantly depending on the characteristics of national cultures. The criteria for differentiation are the distance of power between managers and subordinates and the degree of formalization. The scale of TNCs, multi-tiered hierarchical management structure, dictates the need for significant formalization of various aspects of staff work, increasing the distance between employees at different levels of the management hierarchy. Excellent institutional structure, the business model of digital platforms objectively assumes the maximum democratization of corporate culture both within the organizational core of digital platforms and between it and participants of the ecosystem. The focus on innovation as a condition and way of existence of digital platforms necessitates the creation and maintenance of a creative atmosphere of an incubator of new ideas. The basis for raising the status of the employee is his creative achievements, ensuring the innovative development of the platform. The staff looks like colleagues in the creative process, working on a single wave. "Creative diffusion" of the creative atmosphere in the team enhanced by the need for rapid response to network signals, the ecosystem of the information platform.

Reliance on data as a key asset and business tool distinguishes digital platforms from traditional TNCs. It provides the competitive advantages of high mobility, ability to respond quickly, adapt to market changes, easily overcome spatial constraints, expanding its activities globally. With the spread of information technology, the constructed data on which all the activities of the digital platforms are located become important fixed assets. In turn, the technical infrastructure of their processing is converted into working capital, which can be outsourced to a third-party supplier (cloud platforms). As a result, in terms of mobility potential, information platforms are on a par with financial corporations. At the same time, unlike the fixed assets of TNCs, databases, yielding to the liquidity of banknotes, can be easily replenished, rebuilt, and aimed at providing new areas of work, meeting a wide range of constantly updated needs of different consumer groups, regardless of their location.

The effect of the scale of production (savings on transformation costs per unit of output due to fixed costs), as a source of benefits for TNCs, is complemented by the effect of the scale of consumption (additional profit by expanding sales without additional transformation and minimum transaction costs).

All this allows researchers to talk about the formation in the digital economy of digital platforms - miniTNCs. Remaining small and medium-sized enterprises in terms of staff and volume of tangible assets, at the same time, in terms of global coverage, the huge scale of activity, and level of competitiveness, are quite comparable with the world's leading TNCs (The Rise, 2016). Creative thinking, reliance on innovation, information technology, the initial focus on finding new niches in global markets pave the way for digital platforms ' competitive success in the digital economy. 


\section{FACTORS OF COMPETITIVE ADVANTAGES OF DIGITAL PLATFORMS}

Companies took the cores of the digital platforms as leadership advantages in the competition. They form horizontal network structures that operate in the areas of supply of communication, intermediary services, promotion of goods as a service, production of material goods. Digital platforms - global leaders maintain the experience of TNCs to provide competitive advantages, based on access to significant resources (finance, technology, and human capital), ability to optimize the location of their production facilities on a global scale, awareness of global markets, international management experience. At the same time, they build their strategies using the opportunities for improving the competitive position, provided by the digitalization of the economy, including the following: taking advantage of the virtual nature of the leading factor of production (data) on which digital platforms operate; market entry; formation of multilateral nature of markets. The use of network effects; taking into account the effects of multihoming, associated with the possibility of simultaneous entry into the ecosystem of several digital platforms (parallel presence on the independent roars that they form); use of multi-product and cross-sector effects.

Given that these factors remain important at all levels of digital platforms competition, we will consider them in more detail.

\subsection{The virtual nature of data as a factor in digital platforms' competitive advantage}

Data serves as the main resource of digital platforms' activity. They are pre-collected, processed, formatted, grouped, systematized, analyzed, used for their own needs, or offered in a form convenient for potential consumers. The basis of digital platforms is the collection, accumulation, creation of an information base for managing the movement of human and material resources, providing the consumer with certain data as a stand-alone service, or providing analysis and data exchange in the production of goods and services within global value networks. The use of computer technology allows you to eliminate human labor (a key component of production costs) from the data processing process. After all, their content retains its significance only as a subject of classification, systematization, unification, and regrouping following the tasks.

Reliance on information communication technologies (ICT) provides the ability to interact with participants in the production process in real-time, regardless of geographical location. There is a drastic reduction in transaction costs associated with the need to coordinate their activities.

In addition, traditional TNCs specialize in the creation of tangible goods, each additional unit of which requires new costs. Instead, the cost of data duplication tends to be zero. At the same time, the absence of significant costs of copying data (marginal costs) is combined with the accuracy of reproduction and the ability to almost instantly satisfy the consumer's request, regardless of its location. 


\subsection{Features of digital platforms market entry and the formation of competitive advantages over} hierarchical structures

The main difficulty at the initial stage of creating the ecosystem of a digital platform is the need to simultaneously form a representative user base from both manufacturers and potential users, the "chicken and egg problem" (Caillaud and Jullien 2003).

An advanced integrative version of this strategy is the formation of digital platforms around a product that can interest a certain group of manufacturers, which in turn will lead to digital platforms' customers. On the other hand, digital platforms can be created based on the service orientation of a certain already existing micromarket. An effective way to solve the problem can be to involve key participants in the platform, whose presence will stimulate the process of joining others. On communication platforms, such may be the leaders of public opinion. The founder can focus on independently creating value that can meet the needs of a fairly large group of customers on the one hand of digital platforms. In the future, based on the network effect, digital platforms expand the customer base and the range of products offered, including by attracting customers from the other side.

Already at the stage of creating digital platforms, practices of artificial management of competitive advantages of certain groups of participants as a tool to ensure the competitive position of the platform itself are established. This is crucially due to the peculiarities of the structure of the digital platform's assets and the effect of scale. This practice is an example of the simultaneous combination of two levels of competitive interaction digital platforms - internally and externally.

\subsection{The multilateral nature of markets as a factor of digital platforms competition}

One of the factors determining the peculiarities of competition in the markets formed by digital platforms is their multilateral nature (multi-sided markets). Multi-sided markets - markets that connect several different but complementary consumer groups through information technology use. Traditional one-way markets provide the opportunity to obtain value from one class of users (sellers and buyers of a particular product). In turn, the multilateral market provides for the possibility of simultaneous presence in the market of several complementary categories of participants. Thus, in the case of electronic game markets in this capacity are both manufacturers of game consoles, game developers, and potential consumers of their products. Crossside exchange benefit - the synergetic effect that arises in bilateral and multilateral markets due to the possibility of complementary participation of certain categories of digital platforms users in the process of creating a new product. The use of information technology acts as an additional factor in the transformation of forms and methods of competition. It is also worth noting that increasing competition between producers of goods and services on multilateral digital platforms improves the position of consumers of their services and vice versa. More intense competition stimulates the growth of quantity, variety, and quality of goods offered. At the same time, this leads to an improvement in the competitive position of the platform itself. 


\subsection{Scaling effects}

The effect of production scale, on which TNCs rely in competition, is supplemented in the case of digital platforms by the effect of "consumption scale, network scale", characteristic of network structures.

Network effects - the effects of increasing the value of services that can provide network as a result of increasing the number of network participants - potential consumers of services provided by the network. The effect of savings on the scale of production is achieved through savings on fixed costs per additional unit of output. In turn, network effects increase the potential benefits of participating in the network in the process of expanding the range of its members.

Direct network effects - effects of increasing the potential usefulness of participation in the network due to the growing number of its participants. We can observe their effect on examples from the growing use of conventional wired telephone networks to the formation of such large-scale social networks like Facebook, LinkedIn. Indirect network effects - effects of increasing the potential usefulness of participation in the network. The growing number of potential buyers on eBay makes it more attractive to potential sellers. In turn, the growth of the latter leads to increased competition between them. This in turn contributes to falling prices and improving the quality of goods and services. In the first case, we are talking about increasing the usefulness of the network built as a one-way platform (wired telephone), or for participants on one side of the platform (increasing the number of participants in social networks). The dissemination of information accelerates the probability of establishing contact with the right person increases, the level of trust in the as a whole. In turn, indirect, crossnetwork effects provide an increase in supply and demand, expanding sales opportunities, its diversification, increasing choice, consumer demand, quality of service, their differentiation. The existence of indirect network effects becomes the basis for the use of cross-subsidization by one group of users of the other group.

Along with the positive, researchers distinguish between negative and inverse network effects. Inverse network effects - the effects of changes in the potential usefulness of participation in the network due to the activities of other users.

5.5. Multihoming and effects related to the possibility of simultaneous entry into the ecosystem of several digital platforms

The effect of multihoming helps buyers find the best purchase option in terms of price and quality. However, they also have to spend extra effort to switch from one platform to another in search of a better option. The choice of the buyer may be limited by the need to develop new knowledge and skills about the features of each digital platform, the capabilities of the devices they use. The cost of switching from one digital platform to another is also increasing due to the complexity, if not complete impossibility, of transferring a user's reputation to a new platform. In turn, competition for potential customers in a multi-homing environment encourages them to create additional facilities for them. 
Important factors of choice are the characteristics of the markets, access to which opens participation in the platform, rules of conduct, available services, and financial conditions. Thus, in the case of providing information retrieval services, travel, trade, transport services, the transition of the consumer from one platform to another does not cause significant additional costs. The organizers may limit the parallel presence at several platforms.

\subsection{Multiproductivity, effects related to the possibility of simultaneous coverage of many areas}

Active introduction of digital technologies, network business models, digital platforms, causes rapid transformation of consumer preferences, the emergence of fundamentally new products and services, technologies. According to a survey of leaders of leading companies in 12 sectors of the economy up to $40 \%$ of innovations that radically changed the proposed products and business models in such areas as tourism, technology, telecommunications, education, finance, health, services, belonged to the subjects farms that have expanded beyond their industry (Bradley 2015,9-10). The example of a successful business model of a company that implemented digital platforms could be seen in the Airbus Company. The Airbus digital transformation office (DTO) has brought the company mature, industrial-grade digital platforms such as Skywise, DDMS (digital design, manufacturing $\&$ services), artificial intelligence, advanced analytics, airlines sciences as well as internet of things. This company operates a manufacturing platform to source around $80 \%$ of its activities from more than 12,000 suppliers worldwide. Using its platform, Airbus can leverage exchange relationships to access external competencies, share products and services across different aircraft types, and stimulate product development with and among its supplier base. Airbus plays a central, orchestrating role within a network of firms, it is still a product-centric business that focuses on the ownership and sale of products. Moreover, Airbus does not view its suppliers as being required to interact with its customers. Hence, in contrast to multi-sided platforms, the interaction here between different sides is not a condition for value creation in manufacturing platforms.

The introduction of a business model based on the use of a digital platform leads to the destruction of the borders that separated the traditional sectors of the economy. It creates opportunities within a single ecosystem of a digital platform on a competitive basis to unite representatives of different sectors of the economy.

\section{CONCLUSION}

The digital platforms are based on the use of information and communication technologies and data reliance as a key factor in the formation of new value for potential consumers. The key new direction of competitive interaction is the competition between traditional hierarchical and digital platforms-based network 
structures. The radical change in the composition of global market leaders confirms the advantages of the digital platforms as an institutional form and business model open to rapid innovation.

Competition between global platforms - system integrators that create software, form an information base, and a virtual space for the interaction of other digital platforms, is evidence of the contradictory consequences of the tendency to monopolize the markets formed by digital platforms. The possibility of improving, due to the network effects of scaling, quality, and price characteristics of the service of ecosystem participants is combined with an increased risk of abuse of the core of the digital platform by its monopoly position.

A significant impact on the competitiveness of digital platforms has their ability to integrate into a single production process of participants related to different areas of production and regions of the world. The result is the formation of fundamentally new products that can combine and replace the functions of several, displacing the predecessors, the regionalization of international trade while maintaining the globalization of production within value networks.

Such new spheres of competition as competition between digital platforms operating in one market, competition between organizers and clients under the best conditions of redistribution of value-added, competition between clients are becoming widespread.

The precondition for digital platforms' success in competing with traditional institutional forms was the use of innovative tools to gain market advantages. These include the use of the advantages of the virtual nature of the leading factor of production (data). The digital platforms operate; change the structure of market entry costs; format the multilateral nature of markets (reliance on the effect of the advantage of exchange between the parties); use of network effects (direct, indirect, inverse, positive and negative, changes of parties). The usage of a platform business model will contribute to the successful integration of the international economic space.

FUNDING: The authors did not receive any external funding.

CONFLICT OF INTEREST: The authors declare no conflicts of interest.

\section{REFERENCE}

1. Armstrong, M. (2006). Competition in Two-sided Markets. The RAND Journal of Economics, 37 (3), 668-691. DOI https://doi.org/10.1111/j.1756-2171.2006.tb00037.x

2. Bradley, J., Loucks J., Macaulay J., Noronha A. \& Wade M. (2015). Digital Vortex. How Digital Disruption Is Redefining Industries. Lausanne. MD Global Center for Digital Business 
Transformation. Available at: https:/www.cisco.com/c/dam/en/us/solutions/collateral/industrysolutions/digital-vortex-report.pdf

3. Caillaud, B. \& Jullien, B. (2003). Chicken \& Egg: Competition Among Intermediation Service Providers. RAND Journal of Economics, 34(2), 309-328. Available at: https://www.jstor.org/stable/1593720 DOI: https://doi.org/10.2307/1593720

4. Casadesus-Masanell R. \& Ruiz-Aliseda F. (2009). Platform Competition, Compatibility, and Social Efficiency. NET Institute. Working Paper, 08.32. NET

Institute. https://dx.doi.org/10.2139/ssrn.1287439

5. Chui, M. \&, Manyika, J. (2015) Competition at the digital edge: 'Hyperscale' businesses. McKinsey Quarterly. Available at: https://www.mckinsey.com.br/ /media/McKinsey/Industries/Technology\%20Media\%20and\%2 0Telecommunications/High\%20Tech/Our\%20Insights/Competition\%20at $\% 20$ the $\% 20$ digital $\% 20 \mathrm{e}$ dge $\% 20$ Hyperscale $\% 20$ businesses/Competition $\% 20$ at $\% 20$ the $\% 20$ digital $\% 20$ edge $\% 20 \% 20 \% 20 \mathrm{Hy}$ perscale\%20businesses.pdf.

6. Coase, R. (1937). The Nature of the Firm. Economics, 4, 386-405. Available at: https://books.google.com/books?hl=en\&lr=\&id=VXIDgGjLHVgC\&oi=fnd\&pg=PA18\&dq=6. $\% 09$ Coase,+ R. $+(1937) .+$ The + Nature + of + the + Firm.+ Economics,$+4 \&$ ots $=$ RJaknmOu2\&sig=vTZBPlmpWpKxAbnTooo1Lj43sDo

7. Doganoglu, T. \& Wright, J. (2010). Exclusive Dealing with Network Effects. International Journal of Industrial Organization, 28 (2), 145-154. https://doi.org/10.1016/j.ijindorg.2009.07.006

8. Duch-Brown, N. (2017). The Competitive Landscape of Online Platforms. JRC Digital Economy Working Paper. 2017-04. Seville, Joint Research Centre. Available at: https://www.econstor.eu/handle/10419/202226

9. Evans, D.(2003). The Antitrust Economics of Multi-Sided Platform Markets. Yale Journal on Regulation, 20, 325-381. Available at: https://heinonline.org/HOL/LandingPage?handle=hein.journals/yjor20\&div=13\&id=\&page=

10. Evans, D. \& Schmalensee, R. (2007). The Industrial Organization of Markets with Two-Sided Platforms. Competition Policy International, 3 (1) 151-179. Available at: https://www.competitionpolicyinternational.com/the-industrial-organization-of-markets-withtwo-sided-platforms/

11. Haucap, J. \& Heimeshoff, U. (2013). Google, Facebook, Amazon, eBay: Is the Internet Driving Competition or Market Monopolization? DICE Discussion Paper, 83. Düsseldorf. Düsseldorf Institute for Competition Economics. Available at: https://www.econstor.eu/bitstream/10419/68229/1/73435858X.pdf

12. Hyrynsalmi, S., Suominen, A. \& Mantymaki M. (2016). The Influence of Developer Multi-homing on Competition Between Software Ecosystems. The Journal of Systems and Software, 111, 119127. https://doi.org/10.1016/j.jss.2015.08.053

13. Hrytsenko A. (2013). 1.1. The ratio of hierarchy and network as the main structural and organizational problem of modern society / Hierarchy and networks in the institutional architectonics of economic systems. Kyiv.: IEP NAS of Ukraine, p. 143-161.

14. Laffont, J. \& Tirole J. (2001). Competition in Telecommunications. Cambridge, Masssachusetts. MIT press. Available

at: $\underline{\text { https: //books.google.com/books?hl=en\&lr=\&id=ucS5F4lg6TkC\&oi=fnd\&pg=PR7\&dq=14. } \% 0}$ 9Laffont, $+\mathrm{J} .+\% 26+$ Tirole $+\mathrm{J} .+(2001) .+$ Competition $+\mathrm{in}+$ Telecommunications. + Cambridge\&ots $=\mathrm{v}$ A4QfKJUVd\&sig=b9nigxKg9v2-0Qp8ImjQ rBNinA

15. Lilico, A. \& Sinclair, M. (2017). Dynamic Competition in Online Platforms. Evidence from five case study markets. Digital Platforms report. Available at: https://assets.publishing.service.gov.uk/government/uploads/system/uploads/attachment_data/fil e/602816/Digital_Platforms_report_new_BEIS.pdf

16. MarketCap (2021). Available at: https://companiesmarketcap.com 
17. Nosova, O. \& Pavlov K. (2021). Digital Development: Comparison Analysis. London Journal of Social Sciences, Vol. 1, No 2: 31-40. Available at: https://londonic.uk/js/index.php/ljbeh/article/view/56

18. Nochebuena, C. \& Juárez B. (2019). Competiting Police for Regulation Online Platform in the APEC Region. Mexico City: Federal Telecommunications Institute (IFT).

19. OECD. (2019). Like it or not? The impact of online platforms on the productivity of incumbent service providers. OECD Economics Department Working

Papers. https://doi.org/10.1787/18151973

20. Rochet, J.-Ch. \& Tirole J. (2003). Platform Competition in Two-Sided Markets. Journal of the European Economic Association, 4 (1), 990-1029. Available at: https://academic.oup.com/jeea/article/1/4/990/2280902

21. Schallbruch, M., Schweitzer, H., \& Wambacha, A. (2019). New Competition Framework for the Digital Economy: Report by the Commission Competition Law 4.0. Available at: https://www.competitionpolicyinternational.com/wp-content/uploads/2019/12/CPI-SchallbruchSchweitzer-Wambach.pdf

22. The Rise of Micro-Multinational. (2016). London: HSBC Bank plc. Available at: https://www.sge.com/sites/default/files/static/downloads/The $\% 20$ rise $\% 20$ of $\% 20$ micro $\% 20$ multinationals.pdf

23. van Gorp N., Batura O. (2015). Challenges for Competition Policy in the Digitalised Economy. Study for the ECON Committee, European Parliament. Brussels: Directorate General for Internal Policies Policy Department A: Economic and Scientific Policy. Available at: https://www.proquest.com/openview/d5c8c13110dbe78c829f11ca55d232f0/1?pqorigsite $=$ gscholar $\& \mathrm{cbl}=616298$

\section{About the Author - Olga Nosova}

She is Professor of the Department of Marketing, Management and Entrepreneurship at V.N. Karazin Kharkiv National University, where she is involved in delivering lectures, conducting seminars in International Economics, Macroeconomics, Investment, preparing reports, writing articles for conferences and journals. She investigates foreign direct investment, corporate governance, and regional integration. She was a research scholar at the Kennan Institute for Advanced Studies, Woodrow Wilson International Centre in Washington, DC in 1997. She successfully graduated from the Master Program in Applied Economics at the Institute for Advanced Studies in Vienna and took part in various economic programs at Hebrew University, Central European University, Eurasia Foundation, etc. During 1998-2000 she participated in the joint BelgiumUkrainian project in support new educational program in Ukraine. She worked as visiting professor at the Portland State University, and Free University Berlin. Currently, she investigates system transformation in East Europe. A Ukrainian citizen, she received her Ph.D. in Economics from Kharkiv State University in 1992 and Habilitation in Economics from Kharkiv State University in 2002. 